\title{
The Toxicological Risk Assessment of Dermal Exposure of Patients Exposed to Nickel and Chromium due to Application of Ointments with Marjoram Herb Extract (Majoranae Herbae Extractum) Available in Polish Pharmacies
}

\author{
Kamil Jurowski ${ }^{1}$ (I) Maria Fołta ${ }^{2} \cdot$ Barbara Tatar $^{2} \cdot$ Mehmet Berkoz $^{3} \cdot$ Mirosław Krośniak $^{2}$
}

Received: 4 April 2021 / Accepted: 16 June 2021 / Published online: 30 June 2021

(c) The Author(s) 2021

\begin{abstract}
For elemental impurities that have been studied for transcutaneous absorption, the available data are rarely suitable for proper toxicological risk assessment - there are multiple factors that can influence this dermal absorption. Hence, in our studies, we applied generic and conservative approach - cutaneous permitted daily exposure (CPDE) described in International Conference on Harmonisation's Q3D Guideline on Elemental Impurities (ICH Q3D). The aim of this article is toxicological risk assessment (TRA) of dermal exposure of patients exposed to nickel and chromium due to application of ointments with Marjoram herb extract (Majoranae herbae extractum) available in Polish pharmacies ( $n=5$, because only five manufacturers produce this kind of pharmaceutical products in Poland). To make the appropriate TRA approach, we considered (1) raw results (metal per kg of ointment), (2) one-time administration of applied ointments, and (3) daily exposure versus CPDE. Due to the fact the concentrations of Ni generally present in cutaneous products as impurities are not considered sufficient to induce sensitization, the cutaneous and transcutaneous concentration limits (CTCLs) approach was applied for this element assessment. The toxicological analysis was carried out using microwave-assisted wet digestion with concentrated nitric acid and electrothermal atomization atomic absorption spectrometry. Our results show that the ointments with Marjoram herb extract from pharmacies in Poland represent a potential health hazard to patients; however, there may be a requirement for the monitoring of impurities of nickel in future. To the best of our knowledge, this paper is the first study about nickel and chromium content in ointments with Marjoram herb extract (Majoranae herbae extractum).
\end{abstract}

Keywords Nickel $\cdot$ Chromium $\cdot$ Toxicological risk assessment $\cdot$ Permitted daily exposure $\cdot$ Elemental impurities $\cdot$ Herbal medicinal products

$\begin{array}{ll}\text { Abbreviations } \\ \text { CPDE } & \text { Cutaneous permitted daily exposure } \\ \text { CTCLs } & \begin{array}{l}\text { Cutaneous and transcutaneous concentration } \\ \text { limits }\end{array} \\ \text { EMA } & \text { European Medicines Agency } \\ \text { EIs } & \text { Elemental impurities }\end{array}$

Kamil Jurowski

jurowski.tox@gmail.com

1 Institute of Medical Studies, Medical College, Rzeszów University, Al. mjr. W. Kopisto 2a, 35-959 Rzeszów, Poland

2 Department of Food Chemistry and Nutrition, Medical College, Jagiellonian University, Medyczna 9, 30-688 Kraków, Poland

3 Department of Biochemistry, Faculty of Pharmacy, Van Yuzuncu Yil University, 65080 Van, Turkey
ET AAS Electrothermal atomization atomic absorption spectrometry

ICH Q3D International Council for Harmonization of Technical Requirements for Pharmaceuticals for Human Use

PDE Permitted daily exposure

SD Standard deviation

TRA Toxicological risk assessment

\section{Introduction}

There is no doubt that role of the skin in establishing cutaneous and transcutaneous limits is extremely important [1]. Elemental impurities may be accumulated in the skin or absorbed by this route - Fig. 1 . 


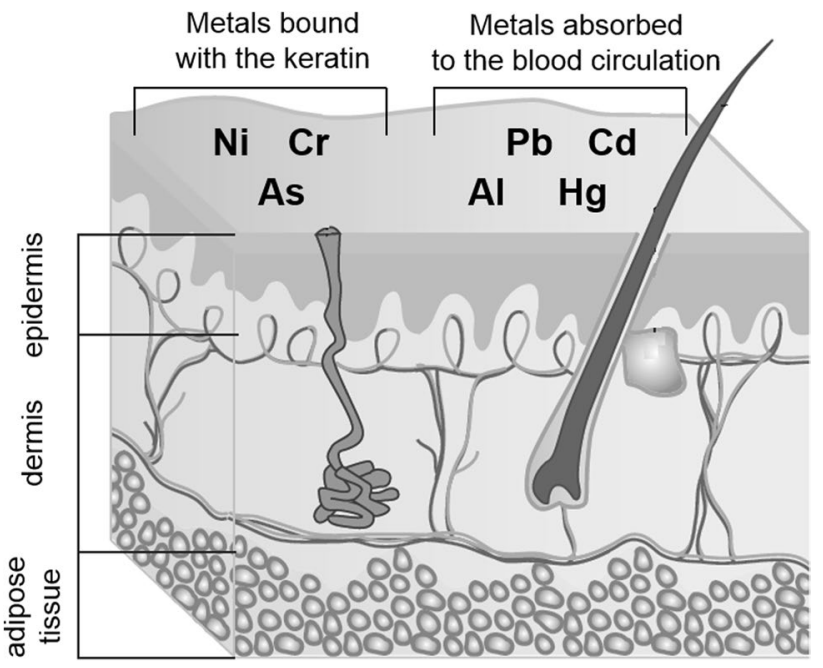

Fig. 1 Elemental impurities accumulation (metals bound with the keratin) in the skin and absorption by the skin (metals absorbed to the blood circulation) — based on [2]

In classical safety assessment of substance applied in products for skin (especially safety assessment of cosmetic products), dermal/transcutaneous absorption is dependent upon the properties of the skin, the anatomical site, the nature of the chemical applied, and the characteristics of the application [3]. Moreover, there are numerous factors that may influence transcutaneous absorption and systemic bioavailability after cutaneous administration of a substance (Fig. 2).

It should be emphasized that there is a lack of studies about evaluation of the systemic absorption of elemental impurities (EIs) via the dermal route [3]. Published experimental data suggest that EIs are usually poorly absorbed through healthy skin even if enhancers are present [1, $3,4]$. Therefore, a conservative and generic strategy of risk characterization has been proposed for EIs by International Conference on Harmonisation's Q3D Guideline
[1]. This conservative, but very important, strategy takes into account application of the parenteral PDE (100\% of bioavailability), to estimate a cutaneous permitted daily exposure (CPDE) using additionally appropriate correction factor (Cutaneous Modifying Factor, CMF). This risk characterization strategy has been estimated for daily/ chronic application to the skin due to exposure for EIs in pharmaceutical products.

Based on literature review [5-7], the EIs in herbal medicine products are not a frequent subject of safety assessment. An interesting but downplayed and forgotten example of herbal medicine products with real and important source of EIs can be ointment with Marjoram herb extract (Majoranae herbae extractum) used adjunctively in rhinitis (runny nose). Marjoram herb extract has been known and used in traditional medicine for centuries, but nowadays is still used as a home remedy for runny nose (especially among young children and seniors) [8].

In scientific literature, there is a lot of articles focused on the determination of essential trace elements and toxic elements in many commercially available products [9-13]; however, there is a lack of studies about sensitizing metals (nickel) and problematic metals (chromium) in pharmaceutical herbal products, like ointment with Marjoram herb extract (Majoranae herbae extractum) used adjunctively in rhinitis (runny nose). To increase the knowledge around the exposure of the assessment of dermal exposure of patients exposed to nickel and chromium due to application of ointments with Marjoram herb extract, we have assessed the levels of these elements in ointments available in Polish pharmacies. In our study, we applied three approaches which are important from the toxicological risk assessment point of view: (1) raw results (metal per $\mathrm{kg}$ of ointment), (2) one-time administration of applied ointments, and (3) daily exposure.

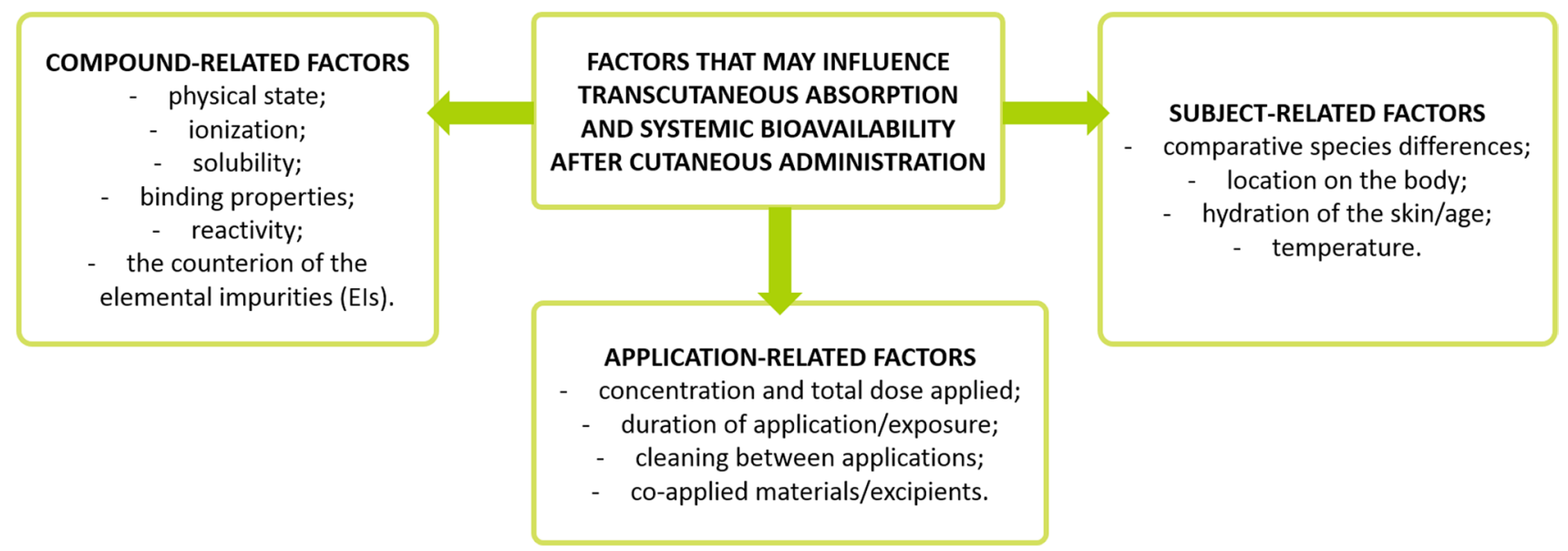

Fig. 2 Factors that may influence transcutaneous absorption and systemic bioavailability after cutaneous administration of a substance - based on [1] 


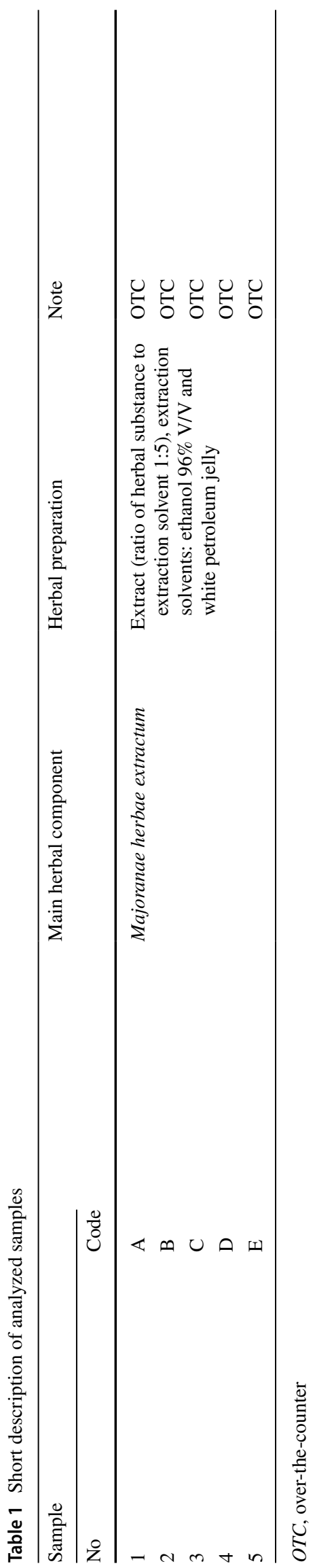

For the reason that the concentrations of Ni generally present in cutaneous products as impurities are not considered sufficient to induce sensitization, the cutaneous and transcutaneous concentration limits (CTCLs) approach was applied for this element assessment. The assessment of dermal exposure of chromium was based on conservative CPDE approach.

\section{Materials and Methods}

\section{Samples and Preparation}

The samples were traditional herbal medicinal products used for relief of irritated skin around the nostrils. All pharmaceutical products $(n=5)$ were ointments with Marjoram herb extract (Majoranae herbae extractum) used adjunctively in rhinitis outfits (runny nose). All products were in semi-solid dosage forms (ointments) for cutaneous use. Majoranae herbae extractum consists of the dried flowering shoots of Origanum majorana $L$. containing not less than $5 \mathrm{~mL} / \mathrm{kg}$ of essential oil (in the dried herbal substance). Usually, small amount of the ointment should be spread around nostrils, two to four times daily.

All herbal medicinal products were purchased from different pharmacies between March 2021 and April 2021 in Niepołomice and Kraków, Rzeszów, Poland. Ointments with Marjoram herb extract were chosen based on availability in Poland (only five manufacturers produce this kind of pharmaceutical products in Poland). To maintain the highest methodological standards, all samples were coded (as A, B, C, D, and E) before studies.

The short description of analyzed ointments tested in this study is described shortly in Table 1.

Until analysis, each ointment was homogenized. Due to the fact all the ointment had an aluminum lid which could be a potential source of EIs, the first few centimeters of each ointment from the tube was discarded. Of each ointment, $0.25 \mathrm{~g}$ was measured, poured into teflon vessels, and digested with $5.0 \mathrm{~mL}$ of concentrated nitric acid (63\%). The closed vessels left at room temperature for $2 \mathrm{~h}$ before microwave digestion. After this step, all samples were digested using microwave digestion system. Five replications were kept and done for all samples. The detailed information about digestion procedure and all instrumental parameters are described briefly in Supplementary Material 1. The samples were later cooled at room temperature $\left(25^{\circ} \mathrm{C}\right)$, and the final volume was made to $20 \mathrm{~mL}$ using ultrapure demineralized water. The cooled samples were stored in plastic bottles as stock sample solutions until analysis. 


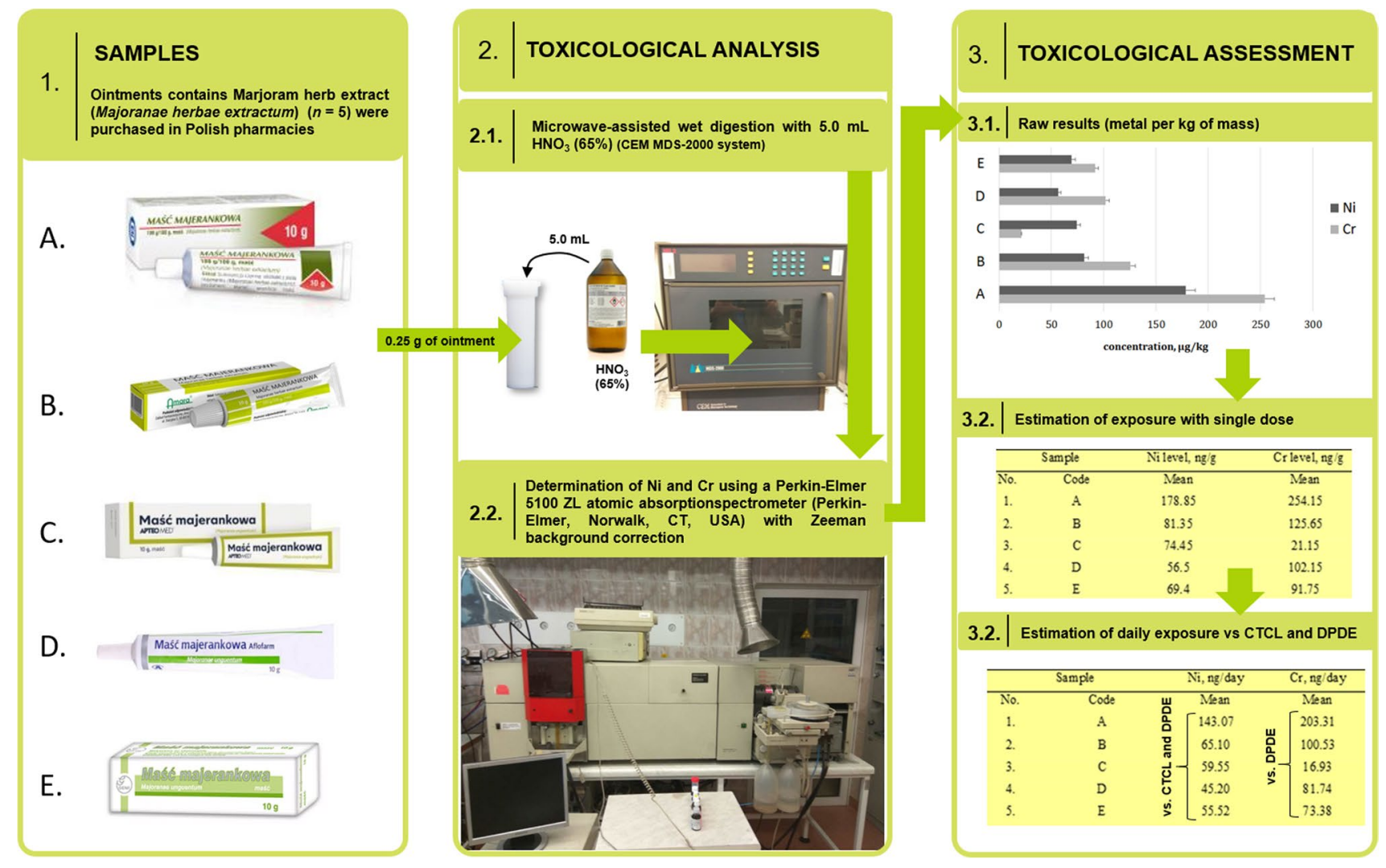

Fig. 3 All steps in the assessment of dermal exposure of patients exposed to nickel and chromium due to application of ointments with Marjoram herb extract (Majoranae herbae extractum) available in Polish pharmacies

\section{Description of Toxicological Analysis}

All steps of our research have been schematically summarized in Fig. 3.

All instrumental parameters, and analytical calibration with quality control approaches are described briefly in Supplementary Material 1. Applied analytical approach was based on our studies published earlier [7, 10]. Five replications were performed for each sample. The quality control and validation of applied methodology are confirmed by previously described studies using the same methodology and apparatus [14].

Data were analyzed using statistical software Origin 2021 Pro The Ultimate Software for Graphing and Analysis (OriginLab Corporation, One Roundhouse Plaza, Suite 303, Northampton, MA 01,060, USA) licensed by the Jagiellonian University in Krakow. The resultant data of five independent replicates (five replicate samples from one tube of each preparation) were expressed as the mean \pm standard deviation.

Fig. 4 The $\mathrm{Ni}$ and $\mathrm{Cr}$ impurities profile of investigated herbal medical products samples (A, $\mathrm{B}, \mathrm{C}, \mathrm{D}$, and $\mathrm{E}$ )

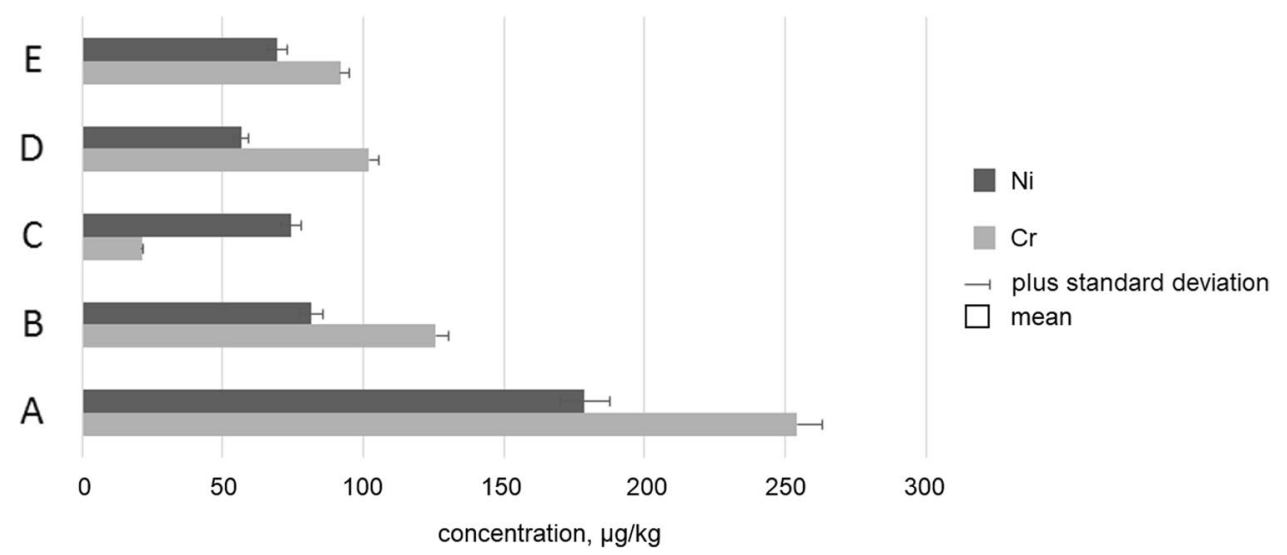




\section{Results and Discussion}

\section{$\mathrm{Ni}$ and $\mathrm{Cr}$ Impurities Profile of Ointments with Marjoram Herb Extract (Majoranae Herbae Extractum) Available in Polish Pharmacies}

The impurities profile of investigated ointments with Marjoram herb extract (Majoranae herbae extractum) available in Polish pharmacies is shown in Fig. 4.

The highest levels of nickel and chromium were in sample A: $178.84 \pm 6.85 \mu \mathrm{g} / \mathrm{kg}$ for $\mathrm{Ni}$ and $254.13 \pm 12.59 \mu \mathrm{g} /$ $\mathrm{kg}$ for chromium. The lowest content of $\mathrm{Ni}$ was in sample $\mathrm{D}(56.51 \pm 3.22 \mu \mathrm{g} / \mathrm{kg})$, and the lowest content of $\mathrm{Cr}$ was in sample C $(21.16 \pm 3.75 \mu \mathrm{g} / \mathrm{kg})$. The nickel levels were similar for all herbal medicinal products $(56.51-81.37 \mu \mathrm{g} /$ $\mathrm{kg})$, except sample A $(178.84 \pm 6.85 \mu \mathrm{g} / \mathrm{kg}$ - three times higher than lowest nickel level in other samples). On the other hand, the chromium level is variable $(21.157-254.13 \mu \mathrm{g} / \mathrm{kg})$. It can be assumed that in general, $\mathrm{Ni}$ levels were approximately similar $($ mean $=92.11 \mu \mathrm{g} /$ $\mathrm{kg}$ ) to $\mathrm{Cr}$ levels (mean $=118.97 \mu \mathrm{g} / \mathrm{kg}$ ).

Very important issue about nickel sensitization potential is the fact that the content of this element present in product applied by dermal route is not clearly correlated sufficiently with the induction of sensitization [1]. Hence, in this situation (similar to Co), the consideration of appropriate concentration limit as the cutaneous and transcutaneous concentration limit (CTCL) [1] is required. The CTCL value for nickel was established by European Medicines Agency (EMA) as $35 \mu \mathrm{g} / \mathrm{kg}$ [1]. Analysis of the obtained results shows that CTCL value was exceeded in all investigated samples. There is no doubt that each product poses a potential allergic risk due to Ni content. For $\mathrm{Cr}$ assessment, additional approaches due to sensitization potential are not required based on ICH Q3D recommendations [1] and Nethercott et al. article [15].

Table 2 The levels of nickel and chromium in analyzed samples (ointment, ng/g)

\begin{tabular}{|c|c|c|c|c|c|}
\hline \multicolumn{2}{|c|}{ Sample } & \multicolumn{2}{|c|}{ Ni level, ng/g } & \multicolumn{2}{|c|}{ Cr level, ng/g } \\
\hline No & Code & Mean & $\mathrm{SD}$ & Mean & SD \\
\hline 1 & A & 178.85 & 8.22 & 254.15 & 12.25 \\
\hline 2 & B & 81.35 & 5.78 & 125.65 & 7.85 \\
\hline 3 & $\mathrm{C}$ & 74.45 & 3.25 & 21.15 & 1.59 \\
\hline 4 & D & 56.5 & 2.31 & 102.15 & 6.45 \\
\hline 5 & $\mathrm{E}$ & 69.4 & 3.44 & 91.75 & 5.44 \\
\hline
\end{tabular}

$S D$ standard deviation

\section{Level of Nickel and Chromium Impurities Including Single Dose of Ointments with Marjoram Herb Extract (Majoranae Herbae Extractum)}

Obtained results of nickel and chromium levels in the ointments with Marjoram herb extract (Majoranae herbae extractum) available in Polish pharmacies are potentially important for other scientist and regulatory affair specialist in pharmaceutical industry (comparative analysis). However, appropriate toxicological risk assessment of investigated metallic elements in this kind of pharmaceuticals should include more information. Required information in this situation is actual level in the one-time administration (single dose) of the product (approximately $0.20 \mathrm{~g}$ ). The levels of nickel and chromium in analyzed samples (ointment, ng/g) are presented in Table 2 .

This step of calculation is indispensable for the next level of toxicological risk assessment - the daily dermal exposure of investigated elements (the maximum daily dose of applied pharmaceuticals).

\section{Estimation of Daily Exposure of $\mathrm{Ni}$ and $\mathrm{Cr}$ Versus Dermal Permitted Daily Exposure (DPDE)}

Based on information in the leaflet for each ointment and information from assessment report on Origanum majorana L. from EMA [8], small amount of the ointment should be spread around nostrils, two to four times daily. The estimated daily exposures to nickel and chromium through applied ointments were calculated considering the maximum use during the day - Table 3 . We use five applications as recommended maximum application to calculate the results from Table 3.

Results from Table 3 show that the estimated exposure of Ni levels is variable (45.20-143.07 ng/day). Additionally, the estimated exposure of $\mathrm{Cr}$ is also variable (16.93-203.31 ng/ day). Considering dermal route and cutaneous bioavailability $(<1 \%[1])$, cutaneous PDE should be applied in toxicological risk assessment. As was mentioned in "Introduction," a generic and conservative approach has been applied for

Table 3 The estimated daily exposure of investigated metals in analyzed ointment (ng/day)

\begin{tabular}{|c|c|c|c|c|c|}
\hline \multicolumn{2}{|c|}{ Sample } & \multicolumn{2}{|c|}{$\mathrm{Ni}$, ng/day } & \multicolumn{2}{|c|}{$\mathrm{Cr}$, ng/day } \\
\hline No & Code & Mean & SD & Mean & SD \\
\hline 1 & A & 143.07 & 8.22 & 203.31 & 12.25 \\
\hline 2 & B & 65.10 & 5.78 & 100.53 & 7.85 \\
\hline 3 & $\mathrm{C}$ & 59.55 & 3.25 & 16.93 & 1.59 \\
\hline 4 & $\mathrm{D}$ & 45.20 & 2.31 & 81.74 & 6.45 \\
\hline 5 & E & 55.52 & 3.44 & 73.38 & 5.44 \\
\hline
\end{tabular}

$S D$ standard deviation 
Table 4 The calculations of cutaneous permitted daily exposure (CPDE) for $\mathrm{Ni}$ and $\mathrm{Cr}$

\begin{tabular}{lll}
\hline & $\mathrm{Ni}$ & $\mathrm{Cr}$ \\
\hline Parenteral PDE $(\mu \mathrm{g} /$ day $)$ & 20 & 1100 \\
$\mathrm{CMF}$ & 10 & 10 \\
$\mathrm{CPDE}(\mu \mathrm{g} /$ day $)$ & 200 & 11,000 \\
\hline
\end{tabular}

Acronyms: $P D E$, permitted daily exposure; $C M F$, Cutaneous Modifying Factor; $C P D E$, cutaneous permitted daily exposure

EIs by International Conference on Harmonisation's Q3D Guideline on EIs based on a systematic adjustment of the parenteral PDE, which assumed $100 \%$ bioavailability, to derive a cutaneous permitted daily exposure by using a Cutaneous Modifying Factor (in most cases - intact/irritated skin $10 ; 100 \% / 10 \%=10)-$ Eq. 1 .

$\mathrm{CPDE}=$ ParenteralPDE $\times \mathrm{CMF}$

where

CPDE - cutaneous permitted daily exposure;

Parenteral PDE - parenteral permitted daily exposure;

$\mathrm{CMF}$ - Cutaneous Modifying Factor.

The calculations of CPDE for $\mathrm{Ni}$ and $\mathrm{Cr}$ based on [1] are shown in Table 4.

This simple, conservative but very useful approach has been estimated for daily/chronic application of pharmaceuticals via dermal route including EIs assessment [1]. The applied toxicological risk assessment approach confirms that the estimated dermal Ni daily exposure $(\mu \mathrm{g} /$ day) is below the CPDE value for this element $(<200 \mu \mathrm{g} /$ day $)$ in all investigated herbal-based pharmaceutical products. It should be recalled that the full assessment of this element should also include allergenic potential [1], what was described in impurities profile section (see earlier). It can be summarized that level of nickel in all investigated medicaments with Marjoram herb extract exceeds the CTCL ( $>35 \mu \mathrm{g} / \mathrm{kg}$, see Fig. 3 and Fig. 4).

On the other hand, the estimated daily exposure of $\mathrm{Cr}$ is significantly variable (16.93-203.31 ng/day). The established by EMA CPDE for this element is $11000 \mu \mathrm{g} /$ day. It can be assumed that all analyzed samples in our studies are characterized by levels of $\mathrm{Cr}$ below the established CPDE. Hence, the applied toxicological risk assessment confirms safety of investigated herbal medicinal product with Marjoram herb extract due to estimated daily exposure of this element.

\section{Conclusions and Recommendations}

The levels of $\mathrm{Ni}$ and $\mathrm{Cr}$ as EIs in all ointments with Marjoram herb extract (Majoranae herbae extractum) available in Polish pharmacies are very low. However, the concentrations of EI generally present in cutaneous products as impurities are not considered sufficient to induce sensitization (especially considering Ni) [1-3]. From this point of view, additional assessment including CTCL was done; level of nickel in all investigated herbal medicinal products exceeds the CTCL ( $>35 \mu \mathrm{g} / \mathrm{kg}$ ). This indicates a potential allergy associated with the presence of nickel in the ointments.

Considering the level of nickel and chromium in single dose of applied ointment, again, is also at a very low level. This simple, conservative but very useful risk characterization strategy has been estimated for daily/chronic dermal route. The toxicological risk assessment approach confirms that the estimated dermal daily exposure of investigated metals in comparison to the CPDE in all products is below established EMA requirements. Hence, the obtained results are in accordance with the standards of directive ICH Q3D.

It can be assumed that analyzed products with Marjoram herb extract in our study represent a health hazard for patients. It should be emphasized that there is a potential risk of nickel allergy (all samples exceed the CTCL). For this reason, a monitoring nickel content in herbal-based pharmaceuticals available in European Union will be desirable. Moreover, herbal medicinal products should be monitored for the presence of other important and potentially hazardous EIs [16-18]. Finally, our results are important and may be significant for other scientist and regulatory affairs working in pharmaceutical industry, especially due to PDE-related topics.

Supplementary Information The online version contains supplementary material available at https://doi.org/10.1007/s12011-021-02798-9.

Author Contribution $\mathrm{KJ}$ and MK wrote the manuscript; they took an active part in experimental research. MB checked the manuscript and made statistical adjustments. BT and MF determined the elements.

Data Availability All data generated or analyzed during this study are included in this published article and its supplementary information file.

Code Availability Not applicable.

\section{Declarations}

Ethical Approval Not applicable.

Consent to Participate Not applicable.

Consent to Publish Not applicable. 
Competing Interests The authors declare no competing interests.

Open Access This article is licensed under a Creative Commons Attribution 4.0 International License, which permits use, sharing, adaptation, distribution and reproduction in any medium or format, as long as you give appropriate credit to the original author(s) and the source, provide a link to the Creative Commons licence, and indicate if changes were made. The images or other third party material in this article are included in the article's Creative Commons licence, unless indicated otherwise in a credit line to the material. If material is not included in the article's Creative Commons licence and your intended use is not permitted by statutory regulation or exceeds the permitted use, you will need to obtain permission directly from the copyright holder. To view a copy of this licence, visit http://creativecommons.org/licenses/by/4.0/.

\section{References}

1. ICH guideline Q3D (R2) on elemental impurities (2020), European Medicines Agency, EMA/CHMP/ICH/353369/2013; Endorsed on 25 September 2020, pp 5-14 https://www.ema. europa.eu/en/documents/scientific-guideline/draft-ich-guidelineq3d-r2-elemental-impurities-step-2b_en.pdf. Currently under public consultation (March 2021)

2. Borowska S, Brzóska M (2015) Metals in cosmetics: implications for human health. J App Tox 35:551-572. https://doi.org/10.1002/ jat.3129

3. SCCS (Scientific Committee on Consumer Safety) (2018) SCCS notes of guidance for the testing of cosmetic ingredients and their safety evaluation 10th revision, SCCS/1602/18 https://ec.europa. eu/health/sites/health/files/scientific_committees/consumer_ safety/docs/sccs_o_224.pdf. Accessed 16 March 2021

4. Hostýnek JJ, Hinz RS, Lorence CR, Price M, Guy RH (1993) Metals and the skin. Crit Rev Tox 23(2):171-235. https://doi.org/ 10.3109/10408449309117116

5. Jurowski K, Krośniak M, Fołta M, Cole M, Piekoszewski W (2019) The toxicological analysis of Pb and Cd by ETAAS in local anaesthetics for teething (teething gels) based on herbs available in Polish pharmacies. Trace Elem Biol Med 52:18-21. https://doi. org/10.1016/j.jtemb.2018.11.005

6. Jurowski K, Krośniak M, Fołta M, Tatar B, Cole M, Piekoszewski W (2019) The toxicological analysis of $\mathrm{Cu}, \mathrm{Mn}$ and $\mathrm{Zn}$ as elemental impurities in pharmaceutical herbal products for teething available in pharmacies in Poland. $\mathrm{J}$ Trace Elem Med Biol 53:109-112. https://doi.org/10.1016/j.jtemb.2019.02.011

7. Jurowski K, Krośniak M, Fołta M, Tatar B, Cole M, Piekoszewski W (2019) Safety assessment of the trace element impurities Ni and $\mathrm{Cr}$ in pharmaceutical herbal products for teething from Polish pharmacies. Biol Trace Elem Res 191(2):517-521. https://doi.org/ 10.1007/s12011-019-1643-8

8. EMA/HMPC/63479/2015 (2015) Committee on herbal medicinal products (HMPC), assessment report on Origanum majorana L., Final version, pp 3-9 https://www.ema.europa.eu/en/docum ents/herbal-report/final-assessment-report-origanum-majorana1-herba_en.pdf. Accessed 16 Mar 2021
9. Jurowski K, Krośniak M, Fołta M, Cole M, Piekoszewski W (2019) The toxicological analysis of lead and cadmium in prescription food for special medical purposes and modified milk products for newborns and infants available in Polish pharmacies. J Trace Elem Med Biol 51:73-78. https://doi.org/10.1016/j.jtemb. 2018.10.007

10. Jurowski K, Krośniak M, Fołta M, Tatar B, Cole M, Piekoszewski W (2019) The toxicological analysis of $\mathrm{Ni}$ and $\mathrm{Cr}$ in prescription food for special medical purposes and modified milk products for babies in infancy available in pharmacies in Poland. Biol Trace Elem Res 192(2):129-135. https://doi.org/10.1007/ s12011-019-01667-w

11. Jurowski K, Krośniak M, Fołta Tatar B, Cole M, Piekoszewski W (2019) The analysis of $\mathrm{Cu}, \mathrm{Mn}$ and $\mathrm{Zn}$ content in prescription food for special medical purposes and modified milk products for newborns and infants available in Polish pharmacies from toxicological and nutritional point of view. J Trace Elem Med Biol 53:144-149. https://doi.org/10.1016/j.jtemb.2019.03.001

12. Kazi TG, Jalbani N, Baig JA, Afridi HI, Kandhro GA, Arain MB, Jamali MK, Shah AQ (2009) Determination of toxic elements in infant formulae by using electrothermal atomic absorption spectrometer. Food Chem Toxicol 47(7):1425-1429. https://doi.org/ 10.1016/j.fct.2009.03.025

13. Taiwo AM, Olukayode S, Ojekunle OZ, Awomeso JA (2021) The toxicological risk assessment of trace elements $(\mathrm{Co}, \mathrm{Cu}, \mathrm{Fe}$, and $\mathrm{Zn}$ ) in snacks from Ijebu Ode, Ogun State, Southwest, Nigeria. Biol Trace Elem Res. https://doi.org/10.1007/s12011-021-02576-7

14. Kasznia-Kocot J, Zachwieja Z, Chłopicka J, Krośniak M (1996) The content of certain trace elements and heavy metals in the hair of children from Chorzów. Pediatr Pol 71(2):31-36

15. Nethercott J, Paustenbach D, Adams R, Fowler J, Marks J, Morton C, Taylor J, Horowitz S, Finley B (1994) A study of chromium induced allergic contact dermatitis with 54 volunteers: implications for environmental risk assessment. Occup Environ Med 51(6):371-80. https://doi.org/10.1136/oem.51.6.371

16. Jurowski K, Fołta M, Tatar B, Berkoz M, Krośniak M (2021) The toxicological risk assessment of lead and cadmium in Valeriana officinalis L., radix (Valerian root) as herbal medicinal product for the relief of mild nervous tension and sleep disorders available in Polish pharmacies. Biol Trace Elem Res. https://doi.org/10.1007/ s12011-021-02691-5

17. Jurowski K, Fołta M, Tatar B, Berkoz M, Krośniak M (2021) Ni and $\mathrm{Cr}$ impurities profile in Valeriana officinalis L., radix-based herbal medicinal product available in Polish pharmacies due to ICH Q3D guideline. Regul Toxicol Pharmacol. https://doi.org/ 10.1016/j.yrtph.2021.104945

18. Jurowski K, Fołta M, Tatar B, Berkoz M, Krośniak M (2021) The toxicological risk assessment of $\mathrm{Cu}, \mathrm{Mn}$, and $\mathrm{Zn}$ as essential elemental impurities in herbal medicinal products with valerian root (Valeriana officinalis L., radix) available in Polish pharmacies. Biol Trace Elem Res. https://doi.org/10.1007/ s12011-021-02779-y

Publisher's Note Springer Nature remains neutral with regard to jurisdictional claims in published maps and institutional affiliations. 